\title{
CURRÍCULO E EDUCAÇÃO COMPARADA: Perspetivas e desafios
}

José Carlos Morgado ${ }^{(*)}$

\section{INTRODUÇÃO}

O currículo e a educação comparada têm vindo recorrentemente a ser associados, parecendo dar a ideia de que estamos em presença de dois campos de estudo que, independentemente da diversidade de práticas, de modelos e de teorias que cada um convoque, se complementam e dimensionam em torno de imperativos comuns: o desenvolvimento de indivíduos autónomos, moral e intelectualmente bem formados, capazes de continuar a aprender ao longo da sua vida e de assumirem uma postura interventiva num cenário social que se transfigura de forma rápida e contínua.

Dito de outra forma, se o currículo é hoje reconhecido como um empreendimento social, um projeto formativo e uma construção partilhada de saberes, num processo que associa a aquisição de conhecimentos à formação da pessoa, a educação comparada pode contribuir para que ele se (re)organize em função de referentes mais consonantes com os tempos atuais, oriundos de distintos contextos tanto nacionais como internacionais. Mais ainda, se a educação encontra na escola o espaço privilegiado para a sua concretização então, a comparação, ao abarcar distintos sistemas educativos, pode ser uma fonte enriquecedora desse processo.

Foi com base nos pressupostos referidos que organizámos esta reflexão. Partindo de uma breve caracterização do panorama social contemporâneo, procuramos analisar, na esteira de Cowen (2013), algumas das principais mudanças no ensino superior, bem como o contributo que a educação comparada tem dado para a implementação de políticas que fizeram com que a universidade deixasse de se legitimar pela aquisição de saber associada à procura da verdade, à formação de cada indivíduo e ao bem-estar social, e se visse compelida a recorrer a outras formas de legitimação, como, por exemplo, a produção de serviços, a performatividade e a economia, numa lógica que tem vindo a subordinar a universidade pública a determinados interesses políticos e económicos.

O texto organiza-se em três segmentos principais. No primeiro, que intitulámos Dinâmicas de mudança e seus reflexos na educação, fazemos referência a alguns processos de mudança social

\footnotetext{
${ }^{(*)}$ Centro de Investigação em Educação. Instituto de Educação, Universidade do Minho E-mail: josecarlosmorgado @gmail.com.
} 
e aos avanços políticos e económicos registados nos últimos anos, bem como aos seus reflexos no campo da educação.

No segundo segmento - que designámos por Educação comparada e ensino superior: que relação? -, partimos do impacto que as mudanças assinaladas têm provocado no edifício educativo para, de seguida, referirmos alguns problemas com que a educação comparada se tem deparado sempre que tenta, como refere Ferreira (2008, p. 136), ir mais além da mera comparação e "encontrar sentido para os processos educacionais".

Por fim, no terceiro segmento, intitulado Desafios políticos, pedagógicos e curriculares, elencamos alguns aspetos que, em nosso entender, se revelam fundamentais para recolocar a própria educação no lugar que merece e inverter certas tendências pragmáticas e mercantilistas que a têm conformado nos últimos anos e que, de forma direta ou indireta, interferem com os propósitos e os processos da educação comparada.

\section{DINÂMICAS DE MUDANÇA E SEUS REFLEXOS NA EDUCAÇÃO}

Se observarmos as mudanças que ocorreram nas últimas quatro ou cinco décadas, nos países mais desenvolvidos, facilmente constatamos que somos espetadores de um conjunto de transformações e acontecimentos inovadores de tal ordem, que não encontramos uma outra etapa na história que tenha obrigado as pessoas a tanto esforço de acomodação e adaptação a novas formas de vida (ESTEVE, 2009).

Dado o espaço limitado a que este tipo de textos está sujeito, referimos apenas três aspetos que nos parecem fundamentais quando se procuram caracterizar essas mudanças.

Em primeiro lugar, o enorme progresso científico e a revolução tecnológica a que assistimos mais recentemente, em particular no domínio das TIC, com reflexos tanto ao nível da produção de instrumentos e técnicas cada vez mais sofisticados, como do volume de informação e conhecimento disponível, aspetos que, apesar de terem contribuído para melhorar a qualidade de vida das pessoas, acabaram por interferir não só na vida quotidiana e no comportamento de cada indivíduo mas também na forma como se organizam, reestruturam e/ou operacionalizam as próprias dinâmicas sociais. Hoje, uma das características mais comuns das sociedades modernas é a rapidez com que as transformações tecnológicas, sociais e culturais ocorrem.

Na opinião de Lipovetsky (2016), essa aceleração resulta de vivermos hoje numa autêntica revolução digital, em grande parte causada pelo nomadismo virtual que resulta da combinação da mobilidade fácil - símbolo da leveza que caracteriza o mundo material - e da Internet. Esta 
revolução digital, a que não é alheio o crescente nomadismo dos objetos e das pessoas, tem reflexos em vários quadrantes sociais, em particular no ensino, uma vez que "poderá transformar radicalmente, a médio ou a longo prazo, tanto a relação pedagógica como os modos de aquisição de conhecimentos" (idem, p. 135).

Associada a esta revolução digital existe uma catadupa de mudanças que tornam o nosso devir cada vez mais dinâmico mas também mais incerto e mais inseguro. A propósito das mudanças com que nos confrontamos recentemente, as palavras de Hargreaves (2012, p. 353) são expressivas:

Vivemos em tempos perigosamente insustentáveis. No mundo desenvolvido, o desejo de progresso interminável e de consumo ilimitado, de prazer imediato e de recompensas no curto prazo, de querer tudo, e de querer agora coloca o nosso planeta e seus habitantes em perigo.

Em segundo lugar, as questões económicas. A esse nível, a passagem de uma ordem estável e previsível, fundada no uso da razão e no respeito pela verdade transmissível, para um tempo pejado de mudanças e incertezas resultante do protagonismo que têm assumido tanto a globalização dos mercados, como a internacionalização da produção, vistas como imperativos para a captação de recursos, para a venda e troca de produtos e para a melhoria da situação financeira de cada país.

Na opinião de Lima (1997, p. 43), os aspetos que acabámos de referir resultam da afirmação do que, há já algum tempo, designou por paradigma de Educação Contábil para se referir a um novo modo de organização e gestão das instituições de ensino superior em Portugal, baseado em "perspetivas gerencialistas e neocientíficas", típicas de setores privados, e que resultam da associação de "elementos diversos, tais como a privatização e a desregulação, o mercado educacional e as políticas de livre escolha, a avaliação institucional, o controle da qualidade e a aferição da eficácia e da eficiência nas organizações educativas”. Um novo modo de organização e gestão que acabaria por contribuir para reconfigurar o próprio conceito de autonomia nas instituições de ensino superior, enclausurando-a numa lógica marcadamente instrumental, "ao serviço de programas de modernização e racionalização de inspiração empresarial e produtivista" (p. 46). Esta situação permitiu que os agentes económicos fossem ganhando algum ascendente em termos educativos, procurando fazer crer que deveria ser o sistema produtivo, a par do desenvolvimento económico do País, a identificar as principais necessidades educativas dos indivíduos.

Em terceiro lugar, o facto de a globalização e a internacionalização terem contribuído para que a atuação de certos organismos supranacionais - Fundo Monetário Internacional (FMI), Banco Mundial (BM), Comissão Europeia (CE), Organização para a Cooperação e Desenvolvimento 
Económico (OCDE) - passasse a interferir e a condicionar as tomadas de decisão dos Estados, que veem definhar cada vez mais o seu poder interventivo e o seu protagonismo em matéria educativa.

Esta interferência, que surge na confluência de vários processos - definiç̧ão de standards, avaliação em larga escala, melhoria da qualidade e da eficiência, importância das estatísticas de educação nas tomadas de decisão -, tem gerado visões estandardizadas da realidade, tem conseguido ocultar determinadas diferenças (BORER; LAWN, 2013) e tem sido fundamental na configuração e concretização das políticas educativas contemporâneas: "a criação e difusão de discursos sobre educação que assumem um carácter de conceitos-chave, difundidos e promovidos como base de boas práticas" (SEABRA, 2015, p. 80).

Só que, estes discursos e os conceitos que veiculam ignoram "a pluralidade dos contextos" e pactuam com a "desterritorialização de políticas" (ib.), facilitando a afirmação do que SteinerKhamsi (2012) designa como reformas viajantes, para identificar reformas que decorrem de políticas que perderam a ligação com os grupos e os contextos onde foram geradas, através da naturalização das decisões locais e consequente externalização, tornando-se por isso mais globais e mais desenraizadas em termos simbólicos, geográficos e temporais.

A este respeito, Steiner-Khamsi (2010) lembra que a descontextualização - a nível político, económico ou social - tem sido uma prática inerente à transferência de políticas e de conceitos educativos, atenuando conflitos na implementação de processos internos de reforma que são alvo de contestação, uma vez que se alimenta a ideia de serem medidas políticas decididas externamente. Demonstrativas destas políticas e destas reformas viajantes são, por exemplo, as mudanças educativas implementadas pelo Governo na anterior legislatura em Portugal, a pretexto da recuperação económica do País e da consequente imposição de medidas mais restritivas. Na opinião de Teodoro (2005), o recurso a organizações internacionais "para legitimar opções que já foram feitas no plano nacional" ou para criar condições para impor medidas para as quais não existem “argumentos ou força política” que as legitimem, começa a ser uma prática cada vez mais comum e já não é uma prática muito nova na Europa.

Ora, o figurino político que referimos acaba, inevitavelmente, por se refletir na educação, em particular no currículo que se desenvolve nas escolas, uma vez que, como reitera Pacheco (2015, p. 1), existe uma "similaridade curricular presente nas governamentalidades centradas em resultados e em standards", numa perspetiva a que não são alheias nem a regulação do espaço nacional da educação por políticas transnacionais e supranacionais, nem a afirmação de "uma nova racionalidade tyleriana". Uma nova racionalidade que o autor (ibid.) considera ser uma 
consequência do movimento global de reforma da educação, direcionado para "a estandardização, a prestação de contas, os testes à larga escala e a competição centrada na lógica de mercado".

Neste processo, que lugar deve ocupar a Educação Comparada, nomeadamente ao nível do Ensino Superior?

\section{EDUCAÇÃO COMPARADA E ENSINO SUPERIOR: QUE RELAÇÃO?}

Ao nível do ensino superior, este movimento global de reforma também produziu efeitos significativos, contribuindo, como referimos na introdução, para "enclausurar" as instituições de ensino superior (IES) numa tríade circunscrita a três imperativos - eficiência, performatividade e competição -, essenciais para se posicionarem nos permanentes rankings internacionais, hoje considerados como referentes incontornáveis nos domínios do reconhecimento e do prestígio académico.

Para configurar essa situação, Cowen (2013, p. 25) considera que contribuíram, pelo menos, dois aspetos, que importa referir.

Desde logo, e existência do que o autor designa por osmose social para se referir à "relação entre o internacional e o doméstico" e aos efeitos que produz na configuração dos padrões universitários e na transformação das universidades em tecnologia social, isto é, um modelo organizacional em que a eficiência se sobrepõe à igualdade de oportunidades, a contribuição económica da instituição se sobrepõe ao seu papel crítico e reflexivo na sociedade e a quantidade de produtos académicos colocados em locais de referência se sobrepõe à sua qualidade. A este respeito, Santos (2013, p. 13) considera que esta transformação não pode ser analisada à margem das atuais políticas educativas, orientadas pelo mercado, que introduzem nas universidades critérios e princípios empresariais e que contribuem para que a "qualidade da produção em termos de originalidade e de consistência teórica ou metodológica" ceda lugar à "pontuação que o periódico em que o artigo foi publicado obteve naquele período".

Em segundo lugar, a transferência de políticas e modelos educacionais, que referimos atrás, que decorre do facto de os políticos, a imprensa e até muitos educadores terem tendência para apontar e seguir países que consideram ter "melhor" serviço educativo e, por isso, serem mais aptos para competir nos mercados internacionais, o que os compele reformarem-se com base na importação de modelos considerados como bem sucedidos nesses contextos.

É precisamente a este nível que a Educação Comparada se torna essencial, uma vez que pode limitar-se a viabilizar a transferência de modelos e relações considerados mais eficazes 
noutros contextos - configurando-se como esteio legitimador de uma universidade rendida aos interesses económicos e, por isso, ancorada em lógicas pragmáticas e utilitaristas - ou, pelo contrário, fazer a diferença, já que, sem deixar de ter em conta as linhas epistemológicas e os princípios éticos dos estudos comparados, contribui para a construção de uma visão crítica de todo esse processo, assumindo-se, como reitera Cowen (2012, p. 377), como "uma área de trabalho intelectual altamente relevante e útil", capaz de contribuir para interpretar os problemas educacionais de âmbito internacional para, a partir desse esforço, compreender e intervir sobre o que se passa em cada contexto mais específico.

Só que, para que isso seja possível, são necessárias algumas mudanças que identifico no segmento seguinte e sem as quais os contributos que a educação comparada pode propiciar para a melhoria educacional ficarão reféns do campo das intenções.

\section{DESAFIOS POLÍTICOS, PEDAGÓGICOS E CURRICULARES}

Neste último segmento, importa identificar alguns desafios que consideramos essenciais para a melhoria do paradigma educativo e para que a Educação Comparada se afirme como uma via propícia para esse fim.

Dos múltiplos desafios que poderíamos identificar, decidimos centrar-nos em quatro aspetos que, pela sua importância, temos vindo a referir há já algum tempo (MORGADO, 2010, 2014).

Em primeiro lugar, a necessidade de a educação se assumir como um desígnio nacional. É preciso que as pessoas compreendam que pensar a educação é pensar a sociedade no seu todo, isto é, no seu património cultural, nos seus valores, nas suas ambições e nas suas utopias. Só assim as instituições públicas de ensino poderão converter-se num espaço de participação social, num referente de cultura e num local de vivência democrática. No fundo, trata-se de reconhecer que é necessário valorizar e dignificar a escola pública, uma vez que se trata de uma escola para todos, sendo imprescindível criar condições e gerar recursos que permitam disponibilizar uma oferta educativa de qualidade. Só que, para que isso aconteça é necessária uma mudança das políticas públicas, devolvendo poderes de decisão ao Estado, que deve assumir um papel central nesse processo, criando mecanismos que facilitem o acesso ao ensino superior e garantam a igualdade de oportunidades, independentemente do estrato socioeconómico de que proveniência de cada indivíduo.

Em segundo lugar, a necessidade de perfilhar um conceito de currículo diferente do que tem imperado no nosso sistema de ensino. Em vez de um conjunto de "matérias" previamente definidas 
e estruturadas centralmente, de forma a serem transmitidas e implementadas na prática [plano], o currículo deve ser assumido como um amplo projeto social e resultar de uma construção participada e de uma partilha assumida de poderes e responsabilidades (MORGADO, 2002), permitindo que os vários intervenientes no processo educativo se sintam corresponsabilizados pela conceção e realização desse projeto formativo comum. Trata-se, como refere Sousa (2004, p. IV), da "passagem de um currículo técnico, pressupostamente asséptico, porque hermeticamente fechado e por isso descontextualizado, para um currículo que toma consciência crítica do seu território enquanto subsistema de um sistema mais amplo onde jogam múltiplas pressões de natureza política, económica, social e cultural". Só que, para que isso seja viável, é necessária uma atualização curricular que envolva, como sugere Jacobs (2014, p. 15), "a substituição de conteúdos, competências e avaliações antiquadas por opções mais atuais", onde pontuem as competências reflexivas e comunicativas, bem como algumas mudanças organizacionais, tanto na forma de agrupar os alunos como na utilização do espaço - tanto físico como virtual.

Em terceiro lugar, e de acordo com o que nos é proposto por Paulston (2012, p. 409), é necessário que na condição de comparativistas estejamos posicionados, e capacitados, para nos assumirmos como "cartógrafos sociais, capazes de traduzir, mapear e comparar perspetivas múltiplas sobre a vida social e educacional”. Só assim será possível, de forma reflexiva, entrar [ou sair] de diferentes constructos da realidade e/ou formas distintas de a contemplar. Esta questão torna-se, ainda, mais pertinente se tivermos em conta, como referimos atrás, a intensificação do vendaval globalizador que nos tem envolvido recentemente, um processo a que não são alheios nem a sofisticação dos meios tecnológicos, nem o aprofundamento de certas interdependências, com destaque para o sector económico, hoje mais vulnerável e necessitado de gestores responsáveis.

Por último, e tendo em conta que um dos objetivos mais consensualizados nos estudos comparados em educação se circunscreve à vontade de "aprender com a experiência estrangeira", identificando aspetos que possam servir de exemplo para cada situação mais localizada, podendo, por isso, "ser tomados como empréstimo" e adaptados a essa situação (PHILLIPS, 2012, p. 497), é necessário, como defende Larsen (2012, p. 492), que os estudiosos da educação comparada tomem consciência de que "existem múltiplas opções metodológicas e epistemológicas" e que, para além do recurso a esse manancial de possibilidades, é preciso "usar a imaginação para vislumbrar novas formas espaciais, visuais e discursivas de verdade". Só assim será possível "desafiar as barreiras que limitam o diálogo e o debate mais amplos", adotar soluções mais imaginativas e posturas mais pluralistas (ibid.), de forma a combater um certo ceticismo que se foi instalando em relação a determinadas narrativas mais totalizantes que pululam no campo da investigação em educação. 
No fundo, uma posição corroborada por Ferreira (2008, p. 136) ao considerar que "a Educação Comparada não pode deixar de inclinar-se para abordagens plurimetodológicas”, o que permitirá obter explicações mais consistentes, necessárias para otimizar o capital social e cultural dos indivíduos, independentemente do contexto em que se encontrem.

\section{CONSIDERAÇÕES FINAIS}

Em jeito de balanço final importa referir que, sem qualquer pretensão de propor soluções definitivas para uma problemática que continua [e continuará] a configurar-se muito complexa, as respostas aos desafios que enunciámos contribuirão para que a educação comparada seja reconhecida como um porto de abrigo que, partindo de respostas que noutros contextos serviram para resolver problemas comuns, seja capaz de gerar explicações para os seus próprios problemas e encontrar caminhos para a sua resolução. Isso será mais fácil se, como reitera Rego (2013, p. 13), aprendermos e trabalharmos num mundo sem fronteiras, o que requer uma educação baseada em pressupostos cosmopolitas, isto é, em "princípios que valorizam a diversidade e a abertura cognitiva a favor de novos laços comunitários e de forças culturais que fortalecem o potencial emancipador da razão e da autonomia humanas".

Porém, não será excessivo lembrar as advertências de Nóvoa e Popkewitz (1992) para o perigo de os estudos comparados se tornarem meramente descritivos, empobrecendo assim o contributo que deveriam propiciar em termos científicos e culturais. Mas, isso dependerá, em última instância, de cada instituição e de cada um de nós.

É que, cumpridos que estejam os desafios que identificámos, a educação comparada estará em condições de poder contribuir para a construção de "um conhecimento mais consciente" e a adoção de "políticas e práticas mais conscienciosas no domínio da educação" (FERREIRA, 2008, p. 138), sendo portadora de um saber com sentido, essencial para a construção de um mundo mais justo e mais democrático. 


\section{REFERÊNCIAS}

BORER, V. L.; LAWN, M. (2013). Governing Educational Systems by Shaping Data: from the past to the present, from national to international perspectives. European Educational Research Journal, 12(1), 48-52. Disp.: <http://dx. doi.org/10.2304/eerj.2013.12.1.48. Acesso em 21 jul. 2016.

COWEN, R. (2012). Introdução editorial: uma nova maneira de pensar. In: COWEN, R.; KAZAMIAS, A.M. (Orgs.). Educação Comparada: Panorama internacional e perspetivas, vol. 2 (p. 377-381). Brasília: UNESCO/ CAPES.

COWEN, R. (2013). A Universidade e atuais desafios: mercado, mobilidade e performatividade. Curitiba: Editora CRV.

ESTEVE, J.M. (2009). Educación y Globalización. La Sociedad y la Economía del Conocimiento. Avances en Supervisión Educativa, $n$. 11. Disp.: http://www.adide.org/revista/index.php. Acesso em 10 jul. 2012.

FERREIRA, A.G. (2008). O sentido da Educação Comparada: uma compreensão sobre a construção de uma identidade. Educação, Porto Alegre, 31 (2), 124-138.

HARGREAVES, A. (2012). Mudança Pedagógica e Educacional para Sociedades do Conhecimento Sustentáveis. In COWEN, R.: KAZAMIAS, A.M. (Orgs.). Educação Comparada: Panorama internacional e perspetivas, Brasília: Unesco/Capes. vol. 2, p. 353-371.

JACOBS, H. H. (2014). Un nuevo currículo esencial para un mundo en cambio. In: JACOBS, H.H. (Ed.). Curriculum XXI: Lo esencial de la educación para un mundo en cambio. Madrid: Narcea Ediciones. p. 11-19.

LARSEN, M.A. (2012). Educação comparada, pós-modernidade e pesquisa histórica: honrando os antepassados. In: COWEN, R.; KAZAMIAS, A.M. (Orgs.). Educação Comparada: Panorama internacional e perspetivas, Brasília: Unesco/Capes. vol. 2, p. 479-495.

LIPOVETSKY, G. (2016). Da Leveza: para uma civilização do ligeiro. Lisboa: Edições 70.

MORGADO, J C. (2002). Autonomia curricular: coerência entre o local e o global. In: FERNANDES, M. et al. O particular e o global no virar do milénio. Lisboa: Colibri. p. 1031-1040.

(2010). Para um outro arquétipo de escola: a necessidade de mudar as políticas e as práticas curriculares. Educação em Revista, 26 (02), 15-42.

. (2014). Currículo e formação contínua de professores em Portugal: dissonâncias entre discursos e práticas. In OLIVEIRA, M.R. (Org.). Professor, formação, saberes e problemas. Porto: Porto Editora. p. 67-90.

NÓVOA, A.; POPKEWITZ, T.S. (1992). Reformas educativas e formação de professores. Lisboa: Educa.

PACHECO, J.A. (2015). Impacto de políticas transnacionais na escola e no trabalho docente. VI ENDIPE. Conferência Inaugural. Goiânia: UEG. (Policopiado).

PAULSTON, R.G. (2012). O mapa da educação comparada depois da pós-modernidade. In: COWEN, R.; KAZAMIAS, A.M. (Orgs.). Educação Comparada: Panorama internacional e perspectivas. Brasília: Unesco/Capes. vol. 2, p. 383-413).

PHILLIPS, D. (2012). Aspetos da transferência educacional. In: COWEN, R.; KAZAMIAS, A.M. (Orgs.). Educação Comparada: Panorama internacional e perspectivas. Brasília: Unesco/Capes. vol. 2, p. 497-515);

REGO, M.A.S. (2013). Introducción. In: REGO, M.Á.S. (Ed.), Cosmopolitismo y Educación: Aprender y trabajar en un mundo sin fronteras. Valencia: BRIEF Ediciones. p. 9-14.

SANTOS, L. (2013). Apresentação. In: COWEN,R. A Universidade e atuais desafios: mercado, mobilidade e performatividade. Curitiba: Editora CRV. p. 9-24.

SEABRA, F. (2015). Empréstimo de Políticas Curriculares em Portugal - 2011-2014. In: MORGADO, J C.; LUNARDI, G.; MOREIRA, A.F.; PACHECO, A. (Orgs.). Currículo, Internacionalização e Cosmopolitismo: desafios contemporâneos em contextos luso-afro-brasileiros. Santo Tirso: De Facto Editores. p. 79-90.

SOUSA, J.M. (2014). Um currículo ao serviço do poder? Tribuna da Madeira, I-IV.

STEINER-KHAMSI, G. (2010). The Politics and Economics of Comparison. Comparative Education Review, 54 (3), 323-342.

Revista Teias v. 18, n. 50, 2017 (Jul./Set.): Conversas sobre formação de professores, práticas e currículos 
STEINER-KHAMSI, G. (2012). Measuring in reinterpreting re-contextualisation. In: VERGER, A.; NOVELLI, M.; ALTINYELKEN, H.K. (eds.). Global Education Policy and International Development. London: Continuum. p. 269-278.

TEODORO, A. (2005). Entrevista. Perspectiva, 23 (1), 223-234. 


\section{RESUMO}

Neste artigo analisa-se a relação entre currículo e educação comparada. Partindo da ideia de que o currículo, como projeto formativo e como construção partilhada de saberes, se deve configurar de modo a garantir o desenvolvimento de indivíduos autónomos, moral e intelectualmente bem formados, capazes de continuar a aprender ao longo da sua vida e de assumirem um papel interventivo numa sociedade que muda de forma rápida e contínua, procura averiguar-se até que ponto a educação comparada contribui para que, no ensino superior, o processo de desenvolvimento do currículo se estruture em função de referentes mais amplos e atuais, oriundos tanto de distintos contextos nacionais como internacionais. A análise permitiu constatar que é necessário diluir certas tendências pragmáticas e mercantilistas que têm conformado o campo do currículo nos últimos anos e que interferem com os propósitos e os processos da educação comparada.

Palavras-chave: Currículo, Educação comparada, Ensino superior.

\section{CURRICULUM AND COMPARED EDUCATION: PERSPECTIVES AND CHALLENGES ABSTRACT}

The relation between curriculum and compared education is analyzed in this article, stemming from the notion that curriculum, as a formative project and a shared construction of knowledges should be configured in order to ensure the development of autonomous, morally and intellectually well-formed individuals, capable of learning continuously throughout their lives and of assuming an active role in a rapidly and ever changing society. We seek to inquire to what extent compared education contributes to curriculum development in higher education being structured around broader and more current referents, originated both nationally and internationally. The analysis led to the understanding that certain pragmatic and market based tendencies which have conformed the curriculum field in recent years and which interfere with the purposes and processes of compared education, must be diluted.

Keywords: Curriculum, Compared education, Higher Education.

\section{CURRÍCULO Y EDUCACIÓN COMPARADA: PERSPECTIVAS Y DESAFÍOS RESUMEN}

En este artículo se analiza la relación entre el currículum y la educación comparada. Partiendo de la idea de que el currículum, como proyecto formativo y cómo construcción compartida del conocimiento, debe asegurar el desarrollo de individuos autónomos, moral e intelectualmente bien entrenados, capaz de seguir aprendiendo durante toda su vida y desempeñar un papel activo en una sociedad que cambia de forma rápida y continua, averiguamos en qué medida, en la enseñanza superior, la educación comparada contribuye para que el desarrollo curricular se estructure en función de supuestos más amplios y actuales, tanto nacionales como internacionales. El análisis permitió concluir que es necesario diluir ciertas tendencias pragmáticas y mercantilistas que han conformado el campo curricular en los últimos años y que interfieren con los propósitos y los procesos de la educación comparada.

Palabras clave: Currículum, Educación comparada, Enseñanza superior.

Submetido em Jul./2017

Aceito em Set./ 2017

Revista Teias v. 18, n. 50, 2017 (Jul./Set.): Conversas sobre formação de professores, práticas e currículos 